\title{
INVESTIGATION OF THE EFFECTS OF DIFFERENT BIAS ANGLES OF STITCHING ON SEAM PERFORMANCE OF WOOL SUITS
}

\author{
Hande Öztaş ${ }^{1}$, Ayça Gürarda ${ }^{*}$ \\ ${ }^{1}$ Textile Engineering Department, Institute of Natural Sciences, Uludag University Bursa, Turkey \\ ${ }^{2}$ Textile Engineering Department, Faculty of Engineering, Uludag University Bursa, Turkey \\ ${ }^{*}$ Corresponding author: aycagur@uludag.edu.tr
}

\section{Abstract:}

Wool suits are always preferred due to their warmth retention in cool weather, comfort, and aesthetic features. Seams are very important for the quality of wool suits. The tensile characteristics of seamed fabric change with the change of fabric bias angle. This study aimed to investigate the effects of different seam angles with various stitch densities on the seam strength and the seam breaking extension of wool suit stitches. In this study, seam strength and seam-breaking elongation at different bias angles were investigated for the stitches of trousers and jackets of wool suits. As is known, in the production of trousers and jackets, the seams are applied not only in the direction of the weft and warp but also in the different bias angles at the crotch area and arm hole seams. Six wool fabrics with different structural properties were chosen as experimental samples. Fabrics were cut at $0^{\circ}, 30^{\circ}, 45^{\circ}, 60^{\circ}$, and $90^{\circ}$ angles and then sewn with three different stitch densities (3, 4, and 5 stitches $/ \mathrm{cm}$ ), with lockstitch stitch type for each fabric angle. Therefore, 90 differently seamed fabric samples were prepared. The results indicated that seams prepared with $0^{\circ}, 45^{\circ}$ and $90^{\circ}$ bias angles give the highest seam strength and that $30^{\circ}, 45^{\circ}$, and $60^{\circ}$ bias angles give the highest seam-breaking elongation values all over the samples. Seams prepared with $30^{\circ}$ and $60^{\circ}$ bias angles give the lowest seam strength, and $0^{\circ}$ and $90^{\circ}$ bias angles give the lowest seam-breaking elongation values all over the samples.

\section{Keywords:}

seam angle, lockstitch, seam strength, stitch density

\section{Introduction}

In recent years, the importance of the wool fabric has increased in the apparel sector. A wool suit is comfortable to use, keeps one warm in cool times of the year, and does not lead to sweat when the temperature rises. Seams are very important for the quality of wool suits. Seam performance is an important factor determining the durability of a garment. The tensile characteristics of the seamed fabric changes with the change of bias angles of stitching and stitch densities. The characteristics of a constructed seam are its appearance, strength, elasticity, and stability, which depend on the type of seam, type of stitch, and the stitch density [1].

The anisotropic nature of textile fabric affects the mechanical properties of fabric stitched at different angles [2]. In garment manufacturing, seams that connect fabric layers in different directions are used [3].

Seam strength can be measured according to the test method of the American Society for Testing and Materials (ASTM) D 1683-04 "Standard test method for failure in sewn seams of woven apparel fabrics" [4]. The ASTM 1683-04 seam strength standard is widely used in the apparel industry for the evaluation of seam strength [5].

Tensile properties of seams are often investigated experimentally or theoretically for vertical directions, but in garments, the stitches are applied in different directions. . Although huge amount of work has been done related to seam strength characteristics $[2,8,9,10]$, research on the strength of the seams applied at different angles is very limited $[6,7]$ and work related to the impact of seam bias angles with different stitch densities in the trouser and jacket stitches of wool suits is very limited. This study is more focused on the performance of seams at the crotch area and the arm hole of trousers and jackets of wool. The effect of changing the stitch densities at different bias angles was also analyzed.

Some of the seams on a garment, such as those on the shoulder seams on a jacket, are not subjected to high levels of stress or extension during use. In contrast, some seams, such as the arm hole seams and the seams at the crotch area of the trousers, are subjected to high levels of stretching during wear [11].

Seam defects such as seam opening and broken stitches are more visible in areas where stresses are high. Seam defect makes a trouser unsuitable for wearing even though the fabric may be in good condition. Therefore, measurement of the seam strength at different bias angles becomes important for garments [12, 13]. The seam patterns for arm, trouser, and blouse are seen in Figure 1. The characteristics of a properly constructed seam depend on the fabric structure and must take into account the strength, extensibility, security, durability, and appearance [14]. Generally, the greater the number of stitches 
Table 1. The properties of fabrics used

\begin{tabular}{|c|c|c|c|c|}
\hline \multirow[t]{2}{*}{ Code } & \multirow[t]{2}{*}{ Weave } & Density (thread/cm) & $\begin{array}{l}\text { Yarn count } \\
(\mathbf{N m})\end{array}$ & \multirow{2}{*}{$\begin{array}{l}\text { Weight } \\
\left(\mathrm{g} / \mathrm{m}^{2}\right)\end{array}$} \\
\hline & & Warp-weft & Warp-weft & \\
\hline $\mathrm{F} 1$ & Twill 2/1 & $33-29$ & 76/2 WO-76/2 WO & 240 \\
\hline $\mathrm{F} 2$ & Plain & $29-24$ & 64/2 WO-32/1 WO & 255 \\
\hline F3 & Twill 2/2 & $39-33$ & 76/2 WO-82/2 WO & 265 \\
\hline $\mathrm{F} 4$ & Twill 3/1 & $37-33$ & 76/2 WO-82/2 WO & 260 \\
\hline F5 & Twill 2/2 & $31-30$ & 76/2 WO-76/2 WO & 255 \\
\hline F6 & Twill 2/2 & $37-28$ & 80/2 WO/PES-64/2 WO & 270 \\
\hline
\end{tabular}
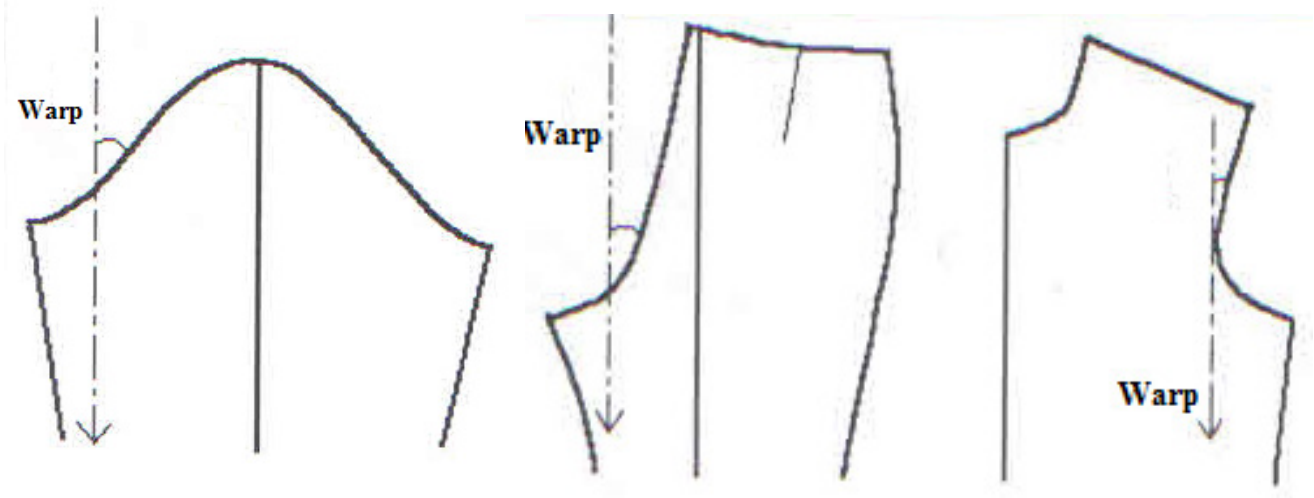

Figure 1. Seam patterns for arm, trouser, and blouse [7].

per inch in a seam, the greater is the seam strength $[15,16]$. Increase in the stitch number causes an increase of the seam strength. It is related to the increase in the number of loops that are stretched simultaneously [13].

In this study, seam strength and seam-breaking elongation at different bias angles were investigated for trouser and jacket stitches of wool suits. As is known, in the production of trousers and jackets, the seams are applied not only in the direction of the weft and warp but also at different bias angles at the crotch area and arm holes. Six different wool fabrics with different properties were used as the investigated material. Fabrics were cut at angles of $0^{\circ}, 30^{\circ}, 45^{\circ}, 60^{\circ}$, and $90^{\circ}$ and then sewn at three different stitch densities $(3,4$, and 5 stitches $/ \mathrm{cm})$ with lockstitch for each fabric angle. Thus, 90 different seamed specimens were prepared. Accordingly, the effects of different seam angles with various stitch densities on the seam strength and the seam-breaking elongation of wool suit stitches were investigated.

\section{Experimental}

\subsection{Materials}

In this research, six different types of woven fabrics that are commonly used to produce wool suits were evaluated. The properties of the fabrics used in this study are shown in Table 1.

\subsection{Methods}

The determination of the seam strength was carried out according to ASTM D 1683-04 "Standard test method for failure in sewn seams of woven apparel fabrics". The samples were stitched on an industrial lockstitch sewing machine (Siruba model). Fabrics were cut at angles of $0^{\circ}, 30^{\circ}, 45^{\circ}, 60^{\circ}$, and $90^{\circ}$ and then sewn at three different stitch densities $(3,4$, and 5 stitches $/ \mathrm{cm}$ ) with lockstitch for each of the fabric angles. Thus, 90 different seamed specimens were prepared. The sewing thread used was $100 \%$ polyester, 80 ticket number core spun yarn. Seam strength tests were done with a Shimadzu AG-X HS model tensile testing machine.

Measurement was done under standard climatic conditions. For each fabric sample, three repetitions of the measurement were made, and the arithmetic mean was calculated from the individual measurement results.

Prior to the tests, all fabric samples were conditioned for 24 hours in standard atmospheric conditions (at a temperature of $20^{\circ} \mathrm{C} \pm 2{ }^{\circ} \mathrm{C}$ and relative humidity of $65 \% \pm 2 \%$ ).

SPSS 14.0 statistical software package was used for conducting all statistical procedures. Completely randomized single-factor (one-way) multivariate analysis of variance (ANOVA) as a fixed model was applied to the data in order to investigate the statistical importance of the effect of stitch density and seam angle on the seam strength and on seam-breaking elongation properties of 


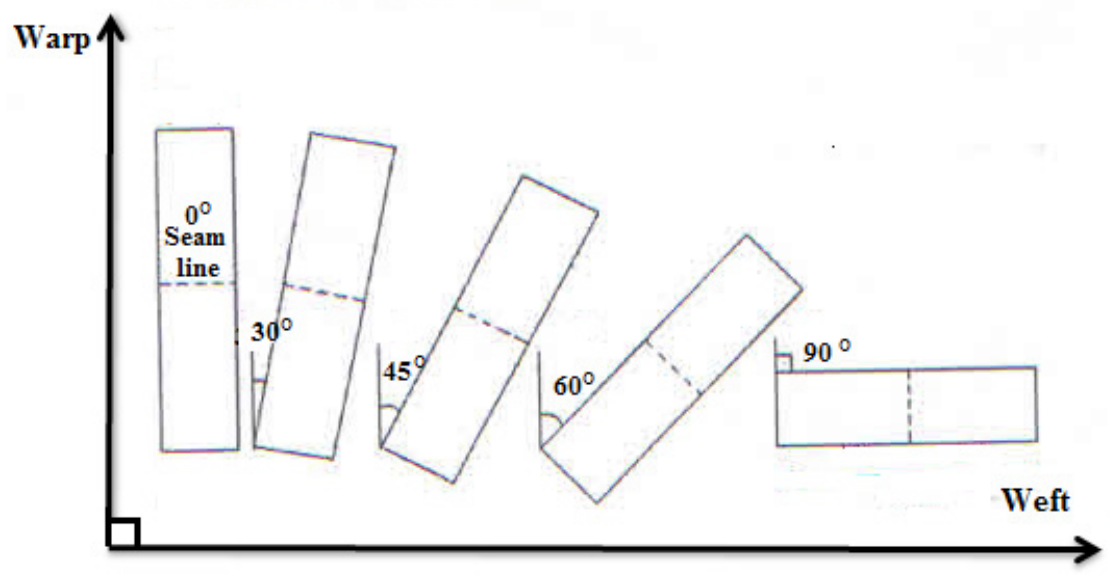

Figure 2. Placement of seam specimens on a fabric at different angles [6].

wool fabrics. The means were compared by Student-NewmanKeuls (SNK) tests. The value of significance level (a) selected for all statistical tests in the study was 0.05 . The treatment levels were marked in accordance with the mean values, and the significance levels marked by different letters (a, b, c, and d) indicate that they were significantly different.

Figure 2 shows the placement of seam specimens on the fabric at different angles.

\section{Results and discussion}

The results of ANOVA and the SNK tests are given in Tables $2-7$. The results of the ANOVA test given in Tables 2-7 indicate that there were statistically significant ( $5 \%$ significance level) differences between the seam strength and between the seambreaking elongation values of fabric samples at different stitch densities $(3,4$, and 5 stitches $/ \mathrm{cm})$ and seam angles $\left(0^{\circ}, 30^{\circ}\right.$, $45^{\circ}, 60^{\circ}$, and $\left.90^{\circ}\right)$.

\subsection{Effect of stitch density on seam strength and seam- breaking elongation}

The ANOVA and SNK test results given in Tables 2-7 indicated that the woven wool fabrics seamed with different stitch densities possessed statistically different seam strengths and seam-breaking elongation values. Fabrics seamed with 5 stitches/cm stitch density gave the highest seam strength and seam-breaking elongation values. Seam strength values increase with increase in stitch density.

It can be seen from Figure 3 that maximum seam strengths of $575 \mathrm{~N}$ and $554.54 \mathrm{~N}$, respectively, were obtained for the fabric sample $\mathrm{F} 1$ seamed at $0^{\circ}$ seam angle with 5 stitches $/ \mathrm{cm}$ and for the fabric sample $\mathrm{F} 1$ seamed at $45^{\circ}$ seam angle with 5 stitches $/ \mathrm{cm}$. It can be seen from Figure 4 that the maximum seam-breaking elongation for the fabric sample F1 seamed at $45^{\circ}$ seam angle with 5 stitches $/ \mathrm{cm}$ was $63.05 \mathrm{~N}$.

In this study, the seam strength and seam-breaking elongation values of fabric samples sewn at $45^{\circ}$ bias angle are higher than those of the others. The results for samples sewn with stitch density of 5 stitches $/ \mathrm{cm}$ often are higher at $45^{\circ}$ bias angle than for those sewn with densities of 3 and 4 stitches $/ \mathrm{cm}$. The increase in stitch number causes an increase in seam strength. It is related to the increase in the number of loops that are stretched simultaneously.

It can be seen from Figure 5 that the maximum seam strength obtained for the fabric sample $F 2$ seamed at $0^{\circ}$ seam angle with 5 stitches/cm was $588 \mathrm{~N}$ and for the fabric sample F2 seamed at $45^{\circ}$ seam angle with 5 stitches $/ \mathrm{cm}$ was $502.54 \mathrm{~N}$. It can be seen from Figure 6 that the maximum seam-breaking elongation value for the fabric sample $\mathrm{F} 2$ seamed at $45^{\circ}$ seam angle with 5 stitches/cm was $61.70 \mathrm{~N}$.

It can be seen from Figure 7 that the maximum seam strength obtained for the fabric sample $\mathrm{F} 3$ seamed at $0^{\circ}$ seam angle with 5 stitches/cm was $728 \mathrm{~N}$ and for the fabric sample F3 seamed at $45^{\circ}$ seam angle with 5 stitches $/ \mathrm{cm}$ was $553.84 \mathrm{~N}$. It can be seen from Figure 8 that the maximum seam-breaking elongation value for the fabric sample $\mathrm{F} 3$ seamed at $30^{\circ}$ seam angle with 5 stitches/cm was $60.13 \mathrm{~N}$.

It can be seen from Figure 9 that the maximum seam strength obtained for the fabric sample F4 seamed at $45^{\circ}$ seam angle with 5 stitches/cm was $509.4 \mathrm{~N}$ and for the fabric sample F4 seamed at $0^{\circ}$ seam angle with 5 stitches $/ \mathrm{cm}$ was $460 \mathrm{~N}$. It can be seen from Figure 10 that the maximum seam-breaking elongation for the fabric sample $\mathrm{F} 4$ seamed at $45^{\circ}$ seam angle with 5 stitches/cm was $57.50 \mathrm{~N}$.

It can be seen from Figure 11 that maximum seam strengths of $664 \mathrm{~N}$ and $561.89 \mathrm{~N}$ were obtained for the fabric sample $\mathrm{F} 5$ seamed at $0^{\circ}$ seam angle with 5 stitches $/ \mathrm{cm}$ and for the fabric sample F5 seamed at $45^{\circ}$ seam angle with 5 stitches $/ \mathrm{cm}$. It can be seen from Figure 12 that the maximum seam-breaking elongation value for the fabric sample F5 seamed at $45^{\circ}$ seam angle with 5 stitches/cm was $65.50 \mathrm{~N}$.

It can be seen from Figure 13 that the maximum seam strength obtained for the fabric sample F6 seamed at $45^{\circ}$ seam angle with 5 stitches/cm was $729.31 \mathrm{~N}$ and for the fabric sample F6 seamed at $0^{\circ}$ seam angle with 5 stitches $/ \mathrm{cm}$ was $664 \mathrm{~N}$. 
Table 2. Statistical analysis (ANOVA and SNK tests) results for seam strength and seam-breaking elongation properties for Fabric no. 1 (F1)

\begin{tabular}{|c|c|c|c|c|c|}
\hline \multicolumn{6}{|c|}{ Results of ANOVA and SNK tests for F1 } \\
\hline \multirow{2}{*}{\multicolumn{2}{|c|}{ Parameters }} & \multicolumn{2}{|c|}{ Seam strength $(\mathrm{N})$} & \multicolumn{2}{|c|}{ Seam-breaking elongation (\%) } \\
\hline & & P-value & SNK ranges & P-value & SNK ranges \\
\hline \multirow{3}{*}{ Stitch density (stitches/cm) } & 3 & \multirow{3}{*}{$0.00^{*}$} & $380.13 a$ & \multirow{3}{*}{0.20} & $41.56 \mathrm{a}$ \\
\hline & 4 & & $413.17 \mathrm{~b}$ & & $42.54 \mathrm{~b}$ \\
\hline & 5 & & $441.58 \mathrm{c}$ & & $44.89 \mathrm{c}$ \\
\hline \multirow{5}{*}{ Seam angle $\left({ }^{\circ}\right)$} & 0 & \multirow{5}{*}{$0.00^{*}$} & $509.30 \mathrm{~d}$ & \multirow{5}{*}{$0.00^{*}$} & $21.13 \mathrm{a}$ \\
\hline & 30 & & $381.60 \mathrm{~b}$ & & $52.94 \mathrm{c}$ \\
\hline & 45 & & $473.21 \mathrm{~d}$ & & $57.77 \mathrm{c}$ \\
\hline & 60 & & $260.92 \mathrm{a}$ & & $53.77 \mathrm{c}$ \\
\hline & 90 & & $433.12 \mathrm{c}$ & & $29.39 \mathrm{~b}$ \\
\hline
\end{tabular}

*Statistically significant $(P<0.05)$. "a", "b", "c", and "d" represent the statistical difference ranges according to the SNK test.

Table 3. Statistical analysis (ANOVA and SNK tests) results for seam strength and seam-breaking elongation properties for Fabric no. 2 (F2)

\begin{tabular}{|c|c|c|c|c|c|}
\hline \multicolumn{6}{|c|}{ Results of ANOVA and SNK tests for F2 } \\
\hline \multirow{2}{*}{\multicolumn{2}{|c|}{ Parameters }} & \multicolumn{2}{|c|}{ Seam strength $(\mathrm{N})$} & \multicolumn{2}{|c|}{ Seam-breaking elongation (\%) } \\
\hline & & P-value & SNK ranges & P-value & SNK ranges \\
\hline \multirow{3}{*}{ Stitch density (stitches/cm) } & 3 & \multirow{3}{*}{0.11} & $379.90 \mathrm{a}$ & \multirow{3}{*}{0.84} & $42.95 \mathrm{a}$ \\
\hline & 4 & & $403.18 \mathrm{a}$ & & $42.75 \mathrm{a}$ \\
\hline & 5 & & 413.77 a & & $42.02 \mathrm{a}$ \\
\hline \multirow{5}{*}{ Seam Angle $\left({ }^{\circ}\right)$} & 0 & \multirow{5}{*}{$0.00^{*}$} & $510.77 \mathrm{c}$ & \multirow{5}{*}{$0.00^{*}$} & $19.64 \mathrm{a}$ \\
\hline & 30 & & $333.39 a$ & & $46.36 \mathrm{c}$ \\
\hline & 45 & & $477.95 \mathrm{c}$ & & $58.48 d$ \\
\hline & 60 & & $292.01 \mathrm{a}$ & & $56.09 \mathrm{~d}$ \\
\hline & 90 & & $380.62 b$ & & $32.30 \mathrm{~b}$ \\
\hline
\end{tabular}

"Statistically significant ( $P$ < 0.05). "a", "b", "c", and "d" represent the statistical difference ranges according to the SNK test.

Table 4. Statistical analysis (ANOVA and SNK tests) results for seam strength and seam-breaking elongation properties for Fabric no. 3 (F3)

\begin{tabular}{|c|c|c|c|c|c|}
\hline \multicolumn{6}{|c|}{ Results of ANOVA and SNK tests for F3 } \\
\hline \multirow{2}{*}{\multicolumn{2}{|c|}{ Parameters }} & \multicolumn{2}{|c|}{ Seam strength $(\mathrm{N})$} & \multicolumn{2}{|c|}{ Seam-breaking elongation (\%) } \\
\hline & & P-value & SNK ranges & P-value & SNK ranges \\
\hline \multirow{3}{*}{ Stitch density (stitches/cm) } & 3 & \multirow{3}{*}{$0.00^{*}$} & $409.01 \mathrm{a}$ & \multirow{3}{*}{0.08} & $38.08 \mathrm{a}$ \\
\hline & 4 & & $445.02 \mathrm{a}$ & & $43.08 \mathrm{~b}$ \\
\hline & 5 & & $511.31 \mathrm{~b}$ & & $43.33 b$ \\
\hline \multirow{5}{*}{ Seam angle $\left(^{\circ}\right)$} & 0 & \multirow{5}{*}{$0.00^{*}$} & $571.81 \mathrm{~d}$ & \multirow{5}{*}{$0.00^{*}$} & $21.46 \mathrm{a}$ \\
\hline & 30 & & $434.81 \mathrm{~b}$ & & $53.49 \mathrm{~d}$ \\
\hline & 45 & & $511.95 \mathrm{c}$ & & $57.00 \mathrm{~d}$ \\
\hline & 60 & & $278.71 \mathrm{a}$ & & $45.21 \mathrm{c}$ \\
\hline & 90 & & $478.29 \mathrm{~b}$ & & $30.32 \mathrm{~b}$ \\
\hline
\end{tabular}

*Statistically significant $(P<0.05)$. "a", "b", "c", and "d" represent the statistical difference ranges according to the SNK test. 
Table 5. Statistical analysis (ANOVA and SNK tests) results for seam strength and seam-breaking elongation properties for Fabric no. 4 (F4)

\begin{tabular}{|c|c|c|c|c|c|}
\hline \multicolumn{6}{|c|}{ Results of ANOVA and SNK tests for F4 } \\
\hline \multirow{2}{*}{\multicolumn{2}{|c|}{ Parameters }} & \multicolumn{2}{|c|}{ Seam strength $(\mathbf{N})$} & \multicolumn{2}{|c|}{ Seam-breaking elongation (\%) } \\
\hline & & P-value & SNK ranges & P-value & SNK ranges \\
\hline \multirow{3}{*}{$\begin{array}{l}\text { Stitch density } \\
\text { (stitches/cm) }\end{array}$} & 3 & \multirow{3}{*}{$0.00^{*}$} & $304.17 \mathrm{a}$ & \multirow{3}{*}{$0.00^{*}$} & $35.82 \mathrm{a}$ \\
\hline & 4 & & $349.93 \mathrm{~b}$ & & $40.18 b$ \\
\hline & 5 & & $360.38 \mathrm{~b}$ & & $40.50 \mathrm{~b}$ \\
\hline \multirow{5}{*}{ Seam angle $\left({ }^{\circ}\right)$} & 0 & \multirow{5}{*}{$0.00^{*}$} & $378.09 \mathrm{c}$ & \multirow{5}{*}{$0.00^{*}$} & 19.48 a \\
\hline & 30 & & $306.81 \mathrm{~b}$ & & $44.72 \mathrm{c}$ \\
\hline & 45 & & $475.34 \mathrm{~d}$ & & $54.79 \mathrm{~d}$ \\
\hline & 60 & & 226.75 a & & $48.91 \mathrm{c}$ \\
\hline & 90 & & $295.89 \mathrm{~b}$ & & $32.77 \mathrm{~b}$ \\
\hline
\end{tabular}

*Statistically significant $(P<0.05)$. "a", "b", "c", and "d" represent the statistical difference ranges according to the SNK test.

Table 6. Statistical analysis (ANOVA and SNK tests) results for seam strength and seam-breaking elongation properties for Fabric no. 5 (F5)

\begin{tabular}{|c|c|c|c|c|c|}
\hline \multicolumn{6}{|c|}{ Results of ANOVA and SNK tests for F5 } \\
\hline \multirow{2}{*}{\multicolumn{2}{|c|}{ Parameters }} & \multicolumn{2}{|c|}{ Seam strength $(\mathrm{N})$} & \multicolumn{2}{|c|}{ Seam-breaking elongation (\%) } \\
\hline & & P-value & SNK ranges & P-value & SNK ranges \\
\hline \multirow{3}{*}{$\begin{array}{l}\text { Stitch density } \\
\text { (stitches/cm) }\end{array}$} & 3 & \multirow{3}{*}{$0.00^{*}$} & $415.40 \mathrm{a}$ & \multirow{3}{*}{0.02} & $43.77 \mathrm{a}$ \\
\hline & 4 & & $481.48 \mathrm{~b}$ & & $45.69 \mathrm{~b}$ \\
\hline & 5 & & $503.79 \mathrm{~b}$ & & $46.95 \mathrm{~b}$ \\
\hline \multirow{5}{*}{ Seam angle $\left({ }^{\circ}\right)$} & 0 & \multirow{5}{*}{$0.00^{*}$} & $566.63 \mathrm{e}$ & \multirow{5}{*}{$0.00^{*}$} & $18.76 \mathrm{a}$ \\
\hline & 30 & & $469.16 \mathrm{c}$ & & $57.99 \mathrm{c}$ \\
\hline & 45 & & $505.70 \mathrm{~d}$ & & $59.73 \mathrm{c}$ \\
\hline & 60 & & 363.68 a & & $58.70 \mathrm{c}$ \\
\hline & 90 & & $429.29 \mathrm{~b}$ & & $32.17 \mathrm{~b}$ \\
\hline
\end{tabular}

"Statistically significant ( $P$ < 0.05). "a", "b", "c", and "d" represent the statistical difference ranges according to the SNK test.

Table 7. Statistical analysis (ANOVA and SNK tests) results for seam strength and seam-breaking elongation properties for Fabric no. 6 (F6)

\begin{tabular}{|c|c|c|c|c|c|}
\hline \multicolumn{6}{|c|}{ Results of ANOVA and SNK tests for F6 } \\
\hline \multirow{2}{*}{\multicolumn{2}{|c|}{ Parameters }} & \multicolumn{2}{|c|}{ Seam strength $(\mathbf{N})$} & \multicolumn{2}{|c|}{ Seam-breaking elongation (\%) } \\
\hline & & P-value & SNK ranges & P-value & SNK ranges \\
\hline \multirow{3}{*}{$\begin{array}{l}\text { Stitch density } \\
\text { (stitches/cm) }\end{array}$} & 3 & \multirow{3}{*}{$0.00^{*}$} & $411.78 \mathrm{a}$ & \multirow{3}{*}{$0.00^{*}$} & $39,12 \mathrm{a}$ \\
\hline & 4 & & $507.83 b$ & & $42.06 \mathrm{~b}$ \\
\hline & 5 & & $589.23 \mathrm{c}$ & & $45.15 \mathrm{c}$ \\
\hline \multirow{5}{*}{ Seam angle $\left({ }^{\circ}\right)$} & 0 & \multirow{5}{*}{$0.00^{*}$} & $529.54 \mathrm{c}$ & \multirow{5}{*}{$0.00^{*}$} & $16.33 \mathrm{a}$ \\
\hline & 30 & & $462.43 \mathrm{a}$ & & $47.70 \mathrm{c}$ \\
\hline & 45 & & $572.81 \mathrm{c}$ & & $57.55 d$ \\
\hline & 60 & & $463.24 \mathrm{a}$ & & $58.54 \mathrm{~d}$ \\
\hline & 90 & & $486.72 \mathrm{~b}$ & & $30.41 \mathrm{~b}$ \\
\hline
\end{tabular}

*Statistically significant $(P<0.05)$. "a", "b", "c", and "d" represent the statistical difference ranges according to the SNK test. 


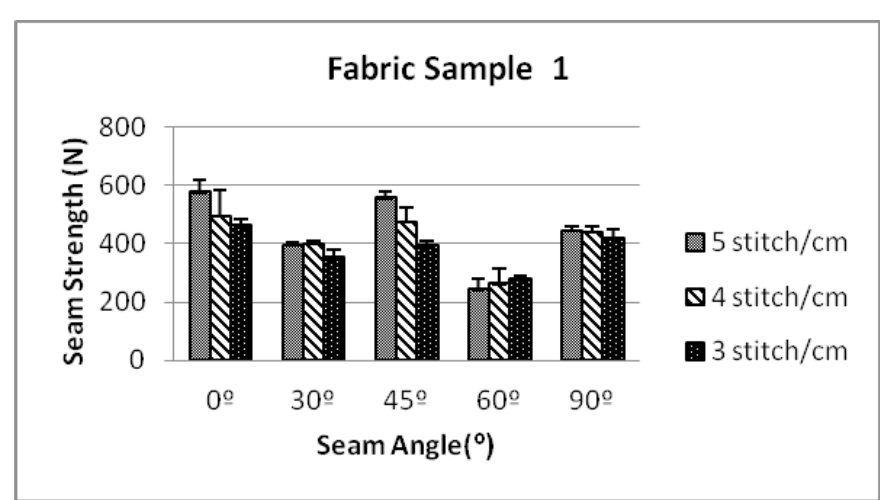

Figure 3. Seam strength values of F1 with different stitch densities at different seam angles.

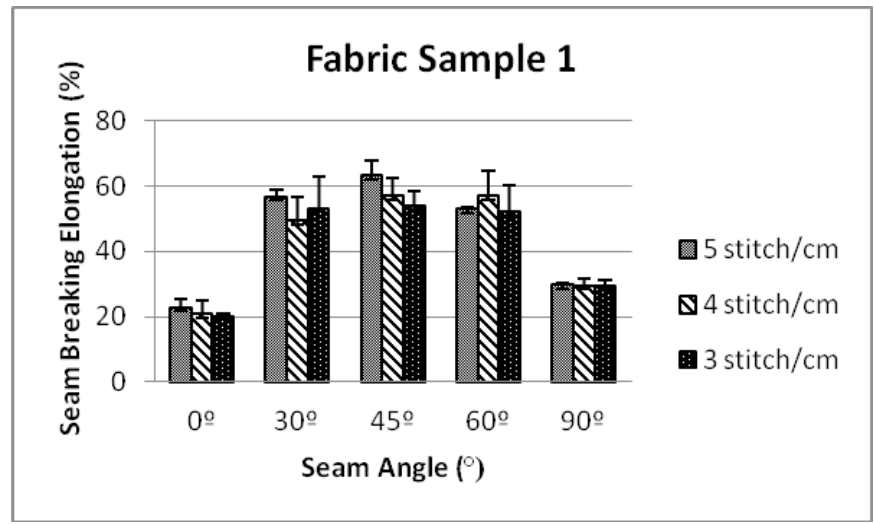

Figure 4. Seam-breaking elongation values of F1 with different stitch densities at different seam angles.

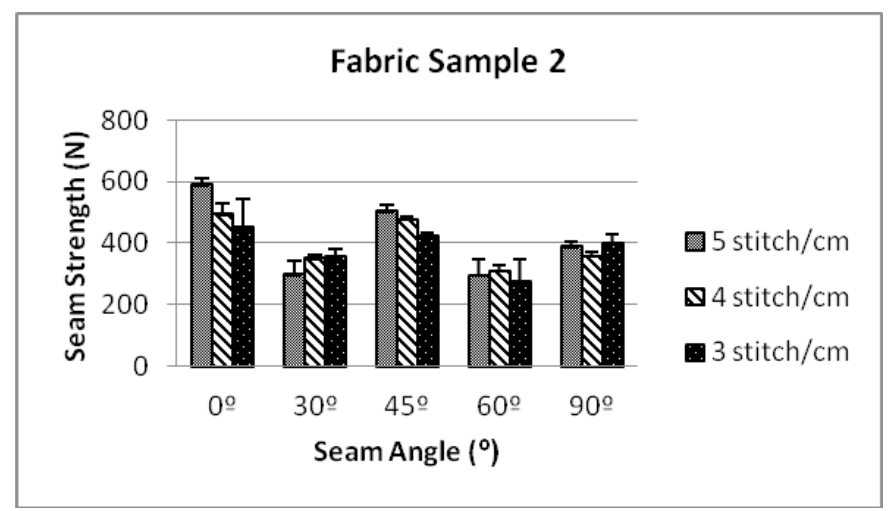

Figure 5. Seam strength values obtained for F2 with different stitch densities at different seam angles.

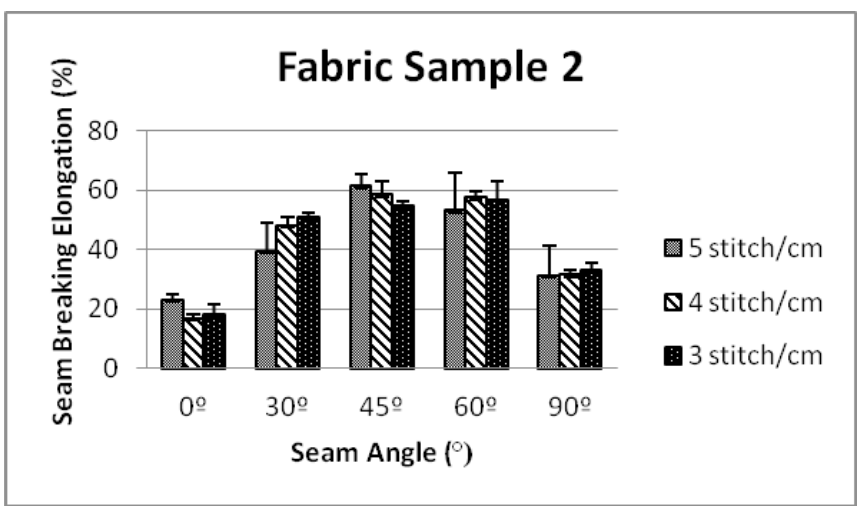

Figure 6. Seam-breaking elongation values obtained for F2 with different stitch densities at different seam angles.

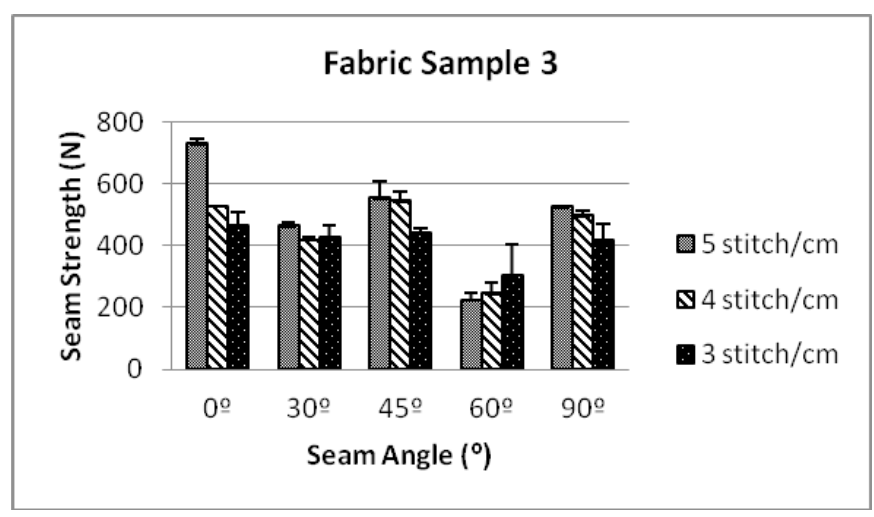

Figure 7. Seam strength values of F3 with different stitch densities at different seam angles.

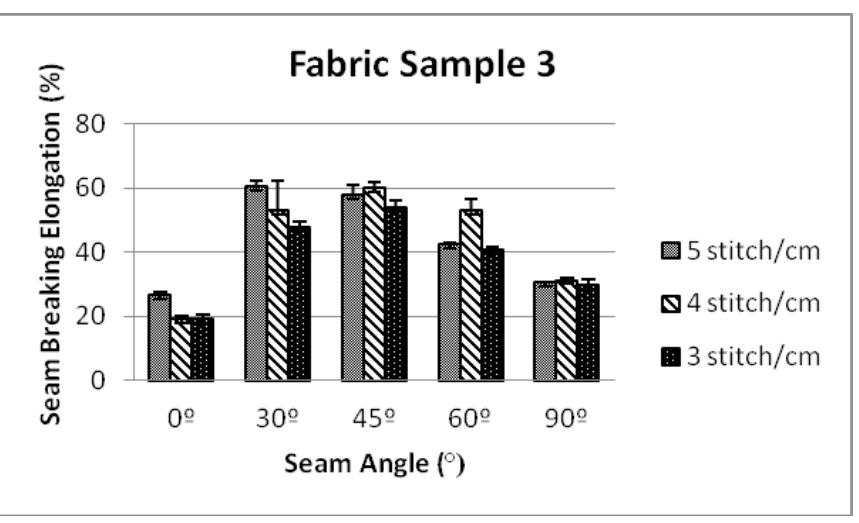

Figure 8. Seam-breaking elongation values of F3 with different stitch densities at different seam angles.

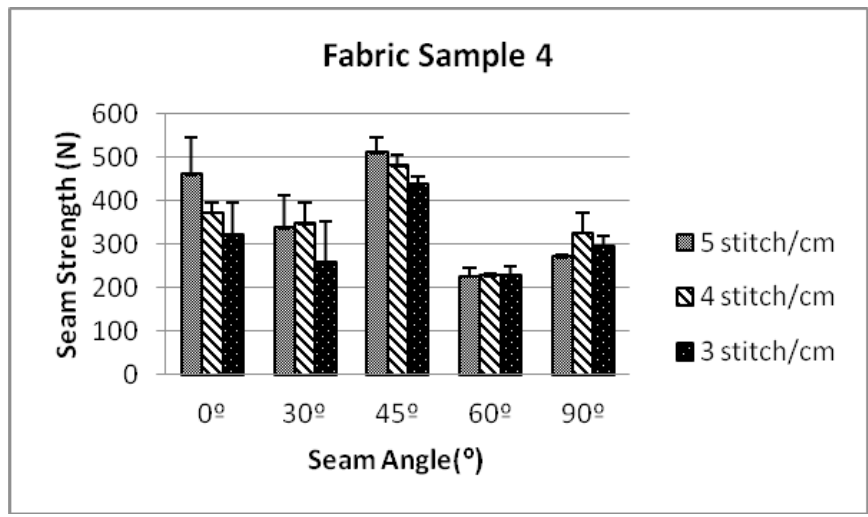

Figure 9. Seam strength values of F4 with different stitch densities at different seam angles.

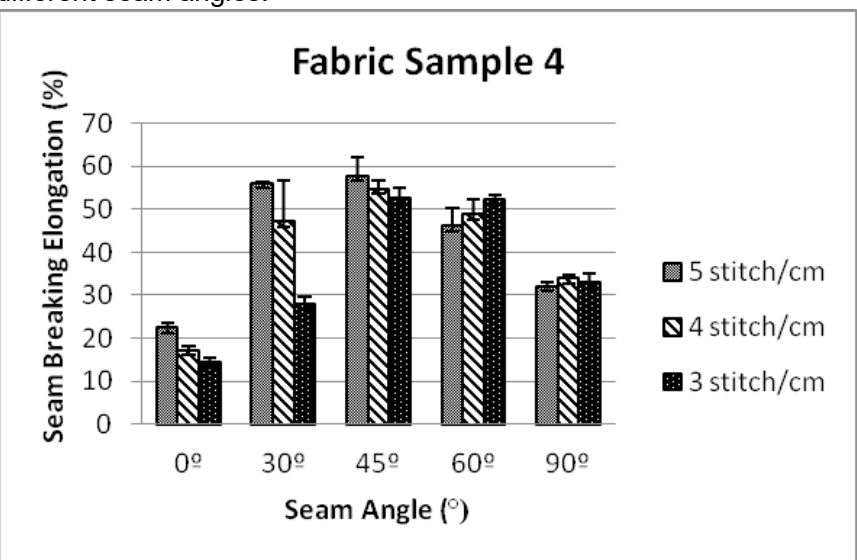

Figure 10. Seam-breaking elongation values of F4 with different stitch densities at different seam angles. 


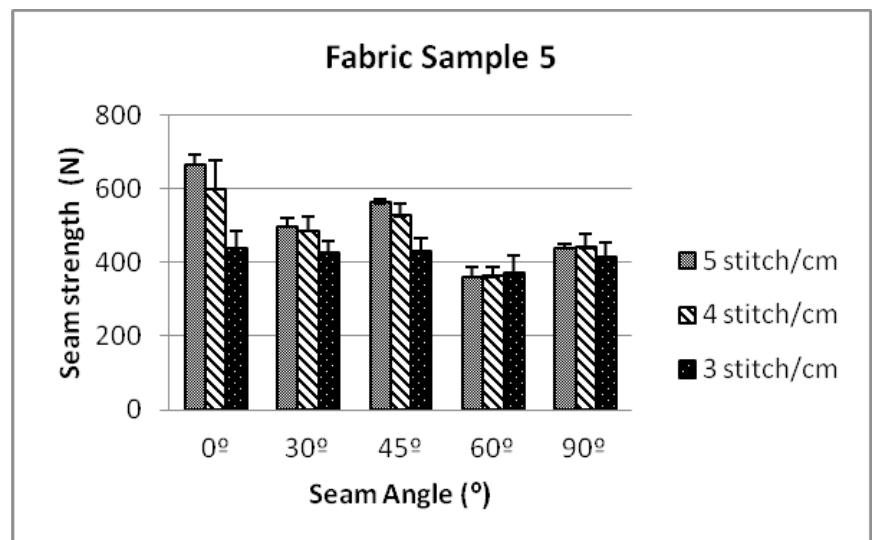

Figure 11. Seam strength values of F5 with different stitch densities at different seam angles.

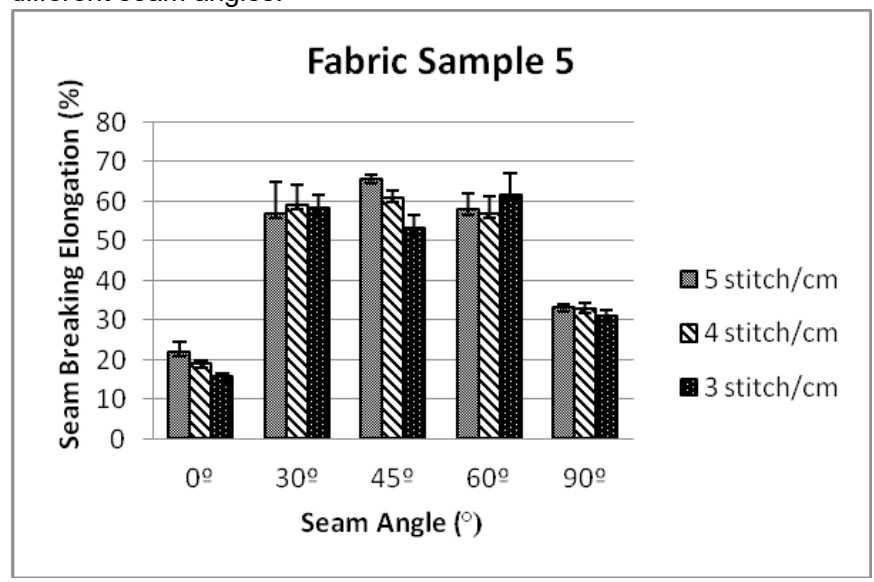

Figure 12. Seam-breaking elongation values of F5 with different stitch densities at different seam angles.

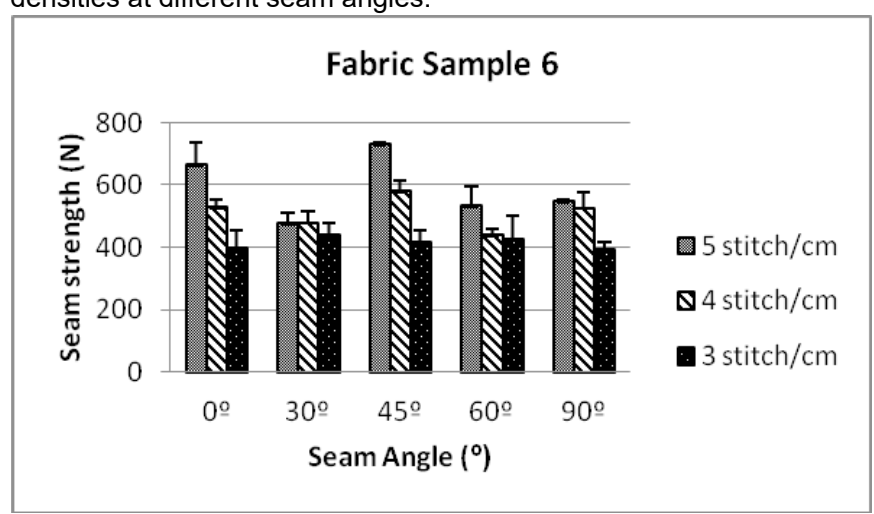

Figure 13. Seam strength values of F6 with different stitch densities at different seam angles.

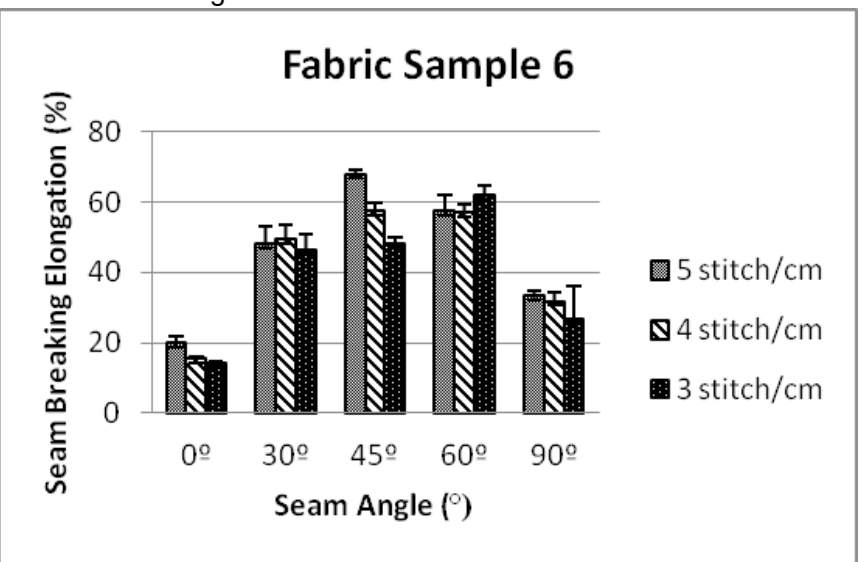

Figure 14. Seam-breaking elongation values of F6 with different stitch densities at different seam angles.
It can be seen from Figure 14 that the maximum seam-breaking elongation value for the fabric sample F6 seamed at $45^{\circ}$ seam angle with 5 stitches/cm was $67.61 \mathrm{~N}$. Seam strength is thus a characteristic determining the performance properties of a seam.

\subsection{Effect of seam angle on seam strength and seam- breaking elongation}

The results of the ANOVA and SNK tests given in Tables 2-7 indicated that the woven wool fabrics seamed at different seam angles possessed statistically different seam strengths and seam-breaking elongation values. Seams prepared with $0^{\circ}$, $45^{\circ}$, and $90^{\circ}$ bias angles gave the highest seam strength and $30^{\circ}, 45^{\circ}$, and $60^{\circ}$ bias angles gave the highest seam-breaking elongation values all over the samples. Seams prepared with $30^{\circ}$ and $60^{\circ}$ bias angles gave the lowest seam strength and $0^{\circ}$ and $90^{\circ}$ bias angles gave the lowest seam-breaking elongation values all over the samples.

As can be seen from the results, the seam strength of the lockstitches at the arm holes of jackets and crotches of trousers in the apparel sector is high when sewn at $45^{\circ}$ bias angle with 5 stitches/cm stitch density.

However, when the lockstitch is applied at $30^{\circ}$ and $60^{\circ}$ bias angles, the seam strength decreases and seam defects, such as broken stitches and seam opening, may ensue. The stitch density of lockstitches at $30^{\circ}$ and $60^{\circ}$ bias angles should be 5 stitches $/ \mathrm{cm}$. Moreover, a stitch density of 5 stitches $/ \mathrm{cm}$ at $30^{\circ}$ and $60^{\circ}$ bias angles should be preferred for high seam strength and elongation rates due to the high stretching at the seams of the arm holes in jackets and crotches in trousers of wool suits during wear.

\section{Conclusions}

In recent years, the importance of the wool fabric has increased in the apparel sector. Wool suits are always preferred due to their warmth-retaining capacity in cool times, comfort, and aesthetic features. Seam performance is very important for the quality of wool suits. The characteristics of a constructed seam are its appearance, strength, elasticity, and stability, which depend on the type of seam, type of stitch, and the stitch density.

Different stitch densities directly affect the seam strength and seam-breaking elongation of wool suits. In a seamed fabric, if the stitch density increases by 3 stitches/cm to 5 stitches/ $\mathrm{cm}$, the seam strength and seam-breaking elongation value increase.

The anisotropic nature of textile fabrics affects the mechanical properties of fabric stitched at different angles. Therefore, measurement of seam strength at different bias angles becomes more important in garments where the joining patterns are not only in the vertical direction but also at different bias angles.

Different bias angles of stitching directly affect the seam 
strength and seam-breaking elongation of wool suits. In a seamed fabric, if the bias angle increases from $0^{\circ}$ to $45^{\circ}$, the seam strength first decreases and then increases up to $45^{\circ}$. If the bias angle continues to increase from $45^{\circ}$ to $90^{\circ}$, the trend of seam strength is almost symmetric from $45^{\circ}$ onward due to the use of a square fabric.

For a seamed fabric, if the bias angle increases from $0^{\circ}$ to $45^{\circ}$, seam-breaking elongation increases up to $45^{\circ}$. If the bias angle continues to increase from $45^{\circ}$ to $90^{\circ}$, the seam-breaking elongation decreases.

In this study, seam strength and seam-breaking elongation of wool suit stitches are influenced by factors such as stitch density and seam angle. As can be seen from the results, the seam strength of the lockstitches at the arm holes of jackets and the crotches of trousers in the apparel sector is high at $45^{\circ}$ bias angle with stitch density of 5 stitches $/ \mathrm{cm}$.

However, when the lockstitch is applied at $30^{\circ}$ and $60^{\circ}$ bias angles, the seam strength decreases and seam defects such as broken stitches and seam opening may ensue. The stitch density of lockstitches at $30^{\circ}$ and $60^{\circ}$ bias angles should be 5 stitches $/ \mathrm{cm}$. A stitch density of 5 stitches $/ \mathrm{cm}$ at $30^{\circ}$ and $60^{\circ}$ bias angles should be preferred for high seam strength and elongation rates due to the high stretching at the seams seen at the arm holes of jackets and crotches of trousers of wool suits.

\section{Acknowledgment}

The authors thank Ipekis Company, Bursa, Turkey, for their contribution to this study.

\section{References}

[1] Ukponmwan, J. O., Mukhopadhyay, A., Chatterjee, K. N. (2000). Sewing threads. Textile Progress, The Textile Institute, 30(3/4), 70-90.

[2] Singh, H., Mukhopadhyay, A., Chatterjee, A. (2016). Influence of bias angle of stitching on tensile characteristics of lapped seam parachute canopy fabric-Part I: mathematical modelling for determining test specimen size. Journal of Industrial Textiles, 46(1), 292-319.
[3] Amirbayat J. (1992). Seams of different ply properties Part I: seam appearance. The Journal of the Textile Institute, 209-217.

[4] ASTM D 1683-04, (1990). Standard test method for failure in sewn seams of woven apparel fabrics. Annual Book of ASTM Standards, USA.

[5] Baharani, M., Shiyamaladevi, P. S. S., Mahendragowda, R.W. (2012). Characterization of seam strength and seam slippage on cotton fabric with woven structure and finish. Research Journal of Engineering Sciences, 1(2), 41-50.

[6] Mukhopadhyay, A., Chatterjee, A., Ahuja, T. (2014). Seam performance of the inseam of a military trouser in relation to garment fit. Textiles and Light Industrial Science and Technology, 3, 29-36.

[7] Çitoğlu, F., Kaya, G. (2011). The effects of sewing thread properties and stitch densities on seam strength at different seam angles. Textile and Clothing, 2, 182-188.

[8] Brain, D. H. (1970). The prediction of strengths of lockstitch seams in woven fabrics. Journal Textile Institute, 61, 493505.

[9] Gurarda, A. (2008). Investigation of seam performance of PET Nylon elastane woven fabrics. Textile Research Journal, 78(1), 21-27.

[10] Carr, H., Latham, B. (1988). The technology of clothing manufacture. Oxford, London, 270-280.

[11] Amirbayat J. (1994). Seams of different ply properties Part II: seam strength. The Journal of the Textile Institute, 84(1), 31-38.

[12] Gardner, F. F., Burtonwood, B., Munden, D. L. (1978). Effect of angle of bias and other related parameters on seam strength of woven fabrics. Clothing Research Journal, 6 , 130-140.

[13] Frydrych, I., Greszta, A. (2015). Analysis of lockstitch seam strength and its efficiency. International Journal of Clothing Science and Technology, 28(4), 480-491.

[14] Seif, M. A. (2016). Identification of seam performance of natural wool textile fabrics. International Design Journal, 6(4), 389-397.

[15] Seetharam, G., Nagarajan, L. (2014). Evaluation of sewing performance of plain twill and satin fabrics based on seam strength and seam efficiency. Journal of Polymer and Textile Engineering, 1(3), 09-21.

[16] Laing, R. M., Webster, J. (1999). Stitches and seams. The Textile Institute, England, 80-100. 